\title{
Anti-Inflammatory Activity of Calendula officinalis L. Flower Extract
}

\author{
Diva Silva ${ }^{1}$, Marta Salvador Ferreira ${ }^{1,2} \mathbb{D}$, José Manuel Sousa-Lobo ${ }^{1,2}$, Maria Teresa Cruz ${ }^{3,4}(\mathbb{D})$ and \\ Isabel Filipa Almeida $1,2, *$ (D)
}

1 Laboratory of Pharmaceutical Technology, Department of Drug Sciences, Faculty of Pharmacy, University of Porto, 4050-313 Porto, Portugal; diva.fsilva@hotmail.com (D.S.); msbferreira@ff.up.pt (M.S.F.); slobo@ff.up.pt (J.M.S.-L.)

2 UCIBIO/REQUIMTE, MedTech, Laboratory of Pharmaceutical Technology, Department of Drug Sciences, Faculty of Pharmacy, University of Porto, 4050-313 Porto, Portugal

3 Faculty of Pharmacy, University of Coimbra, 3004-531 Coimbra, Portugal; trosete@ff.uc.pt

4 Center for Neurosciences and Cell Biology, 3004-504 Coimbra, Portugal

* Correspondence: ifalmeida@ff.up.pt; Tel.: +351-220-428-621

check for updates

Citation: Silva, D.; Ferreira, M.S.;

Sousa-Lobo, J.M.; Cruz, M.T.;

Almeida, I.F. Anti-Inflammatory Activity of Calendula officinalis L.

Flower Extract. Cosmetics 2021, 8, 31.

https://doi.org/10.3390/

cosmetics 8020031

Academic Editor: Enzo Berardesca

Received: 8 April 2021

Accepted: 23 April 2021

Published: 25 April 2021

Publisher's Note: MDPI stays neutral with regard to jurisdictional claims in published maps and institutional affiliations.

Copyright: (C) 2021 by the authors. Licensee MDPI, Basel, Switzerland. This article is an open access article distributed under the terms and conditions of the Creative Commons Attribution (CC BY) license (https:/ / creativecommons.org/licenses/by/ $4.0 /)$.

\begin{abstract}
The use of calendula for its lenitive properties' dates to the XII century. This plant contains several bioactive compounds, including terpenoids, terpenes, carotenoids, flavonoids and polyunsaturated fatty acids. Calendula flower extract is used in soothing cosmetics, such as after-sun, sensitive skin and eye contour products. The anti-inflammatory properties of this ingredient were demonstrated in an animal model, but the mechanism of action is poorly understood. Therefore, our work explored the effect of a calendula flower extract on NO production, a pro-inflammatory radical produced by nitric oxide synthase (iNOS) and highly released by innate immune cells in inflammatory-related pathologies. NO production was evoked by the Toll-like receptor 4 agonist lipopolysaccharide (LPS) in macrophages, using concentrations that did not compromise cells viability. This ingredient exhibited a dose-dependent NO inhibition, reaching $50 \%$ at $147 \mu \mathrm{L} / \mathrm{mL}$ without cytotoxicity. Together with previous literature, these results provide experimental evidence on the anti-inflammatory properties of calendula flower extract, as well as its usefulness in cosmetics with soothing properties and adjunctive skin care in the treatment of the diseases associated with dysregulation of the $\mathrm{NO}$ signaling cascade.
\end{abstract}

Keywords: calendula; anti-inflammatory; NO; skin care; iNOS; soothing cosmetics

\section{Introduction}

Calendula officinalis L. (marigold) belongs to the Asteraceae/Compositae family, which is native to Central Europe and Mediterranean. Its flower oil is the main preparation used in cosmetic products, and contains several bioactive compounds, including terpenoids and terpenes (mainly bisabolol, faradiol, chamazulene, arnidiol and esters), carotenoids (mainly with rubixanthin and lycopene structures), flavonoids, (mainly quercetin, isorhamnetin and kaempferol aglycones) and polyunsaturated fatty acids, (mainly calendic acid) [1-4]. Calendula officinalis L. has been used for medical purposes since the XII century. The plant is reported to present several biological activities namely angiogenic, vascular regeneration, analgesic, antimicrobial, antioxidant and immunomodulatory [5-8]. In cosmetic products, calendula is used in formulations for sensitive skin and soothing products (e.g., after-sun products) among a variety of presentations, including skin, eye, hair and bath products, with recognized safety for use in cosmetics [9].

Several Calendula preparations are available for incorporation in topical formulations directed towards wound healing and for soothing inflamed and damaged skin, like extracts, tinctures, and oils [9]. There are 14 INCI designations for Calendula officinalis L. preparations at the European directory of cosmetic ingredients, and within the same designation, it is 
possible to find botanical preparations with different compositions, depending on the part of the plant and extraction method [10]. Calendula flower extract is the most frequently used in cosmetic products [9]. Although Calendula officinalis L. is often appointed for its anti-inflammatory activity, few studies have addressed this activity [6,11]. Loggia et al. used an animal model to demonstrate that several calendula flower preparations obtained by supercritical $\mathrm{CO}_{2}$ extraction attenuate the inflammation caused by the application of croton oil in mice ears, and that this inflammation reduction was as greater the higher the concentration of faradiol monoester they contained [11]. On the other hand, Preethi et al. showed that calendula flower extract is efficacious for treating both acute (carrageenan and dextran induced) and chronic (formalin induced) inflammation in mice, and they hypothesize it acts by inhibiting pro-inflammatory cytokines (IL-1 $\beta$, IL-6, TNF- $\alpha$ and IFN- $\gamma$ ), COX-2, and subsequent prostaglandin synthesis [6]. Ukiya et al. evaluated the anti-inflammatory activity of isolated compounds from calendula flower extract using the 12-Otetradecanoylphorbol-13-acetate (TPA) induced inflammation ear edema assay in mice, but no assay was performed with the full extract [12]. Although these in vivo studies demonstrate the ability of calendula flower extract to attenuate signs and symptoms of the inflammatory response, mechanistic studies have not been carried out by the authors. Calendula officinalis $\mathrm{L}$. flower ethanol extract exhibited an anti-inflammatory action through the inhibition of pro-inflammatory cytokines (IL- $1 \beta$, IL-6, TNF- $\alpha$ and IFN- $\gamma$ ), and it was proposed to inhibit COX-2 through the inhibition of the enzymes gene and subsequent prostaglandin synthesis. Although, the later action mechanism was not confirmed in experimental studies $[6,13,14]$. Additionally, Braga et al., 2009 studied the effect of a propylene glycol extract of Calendula officinalis L. flowers on reactive oxygen species (ROS) and reactive nitrogen species (RNS) by electron paramagnetic resonance [15]. Noteworthy, there are no reports on the activity of Calendula extracts regarding the inhibition of the strong pro-inflammatory mediator nitric oxide $(\mathrm{NO})$ produced by macrophages in inflammatoryrelated pathologies. Inflammation is triggered by many pathophysiological conditions in response to microorganisms and tissue injury. In the early phases of this process, the first line of defense is provided by macrophages, which in the presence of a stimulus, such as microbial lipopolysaccharide (LPS), a Toll-like receptor 4 agonist, produce several pro-inflammatory mediators, including nitric oxide, cytokines and prostaglandins. Under normal conditions, the release of these molecules is of paramount importance, manifesting severely, rapidly and only for a short period of time upon injury, until the resolution of the harmful stimuli. However, the abnormal production of these pro-inflammatory mediators over a long period of time may evolve to chronic inflammation-related illnesses. Therefore, molecules which are able to mitigate the production of these pro-inflammatory mediators, including NO, present an anti-inflammatory potential [16].

Therefore, to further investigate the anti-inflammatory effect of a commercial Calendula flower extract, a mouse macrophage cell line (RAW 264.7) stimulated with the strong pro-inflammatory stimulus LPS was used in this work. This was done in order to determine the extract's influence on NO production by the inducible iNOS, expressed in innate immune cells including macrophages.

\section{Materials and Methods}

\subsection{Materials}

The calendula flower extract was purchased from Acofarma (Madrid, Spain). It consists of an extract from marigold flowers in refined soy oil, stabilized with tocopherol. The INCI designation of this cosmetic ingredient is "Calendula officinalis L. flower extract". Lipopolysaccharide (LPS) from Escherichia coli (serotype 026:B6) was obtained from Sigma Chemical Co. (St. Louis, MO, USA) and trypsin and fetal calf serum were purchased from Invitrogen (Paisley, UK). All of other reagents were obtained from Sigma Chemical Co. (St. Louis, MO, USA). 


\subsection{Cellular Viability Test (AlamarBlue ${ }^{\circledR}$ )}

In this experiment, macrophages were treated with different concentrations of calendula oil (from 16 to $147 \mu \mathrm{L} / \mathrm{mL}$ ), for $24 \mathrm{~h}$, at $37{ }^{\circ} \mathrm{C}$ and $5 \% \mathrm{CO}_{2} ; 100 \mu \mathrm{L}$ of resazurin solution (final in well concentration of $50 \mu \mathrm{M}$ ) was added and cell cultures were further incubated for $3 \mathrm{~h}$ at $37^{\circ} \mathrm{C}$ protected from light. As only viable cells can reduce resazurin (a non-fluorescent blue dye) into resorufin (pink and fluorescent), their viability correlates with the magnitude of dye reduction. Quantification of resorufin was performed on a Biotek Synergy HT (BioTek Instruments, Winooski, VT, USA) plate reader at $570 \mathrm{~nm}$, with a reference wavelength of $620 \mathrm{~nm}$.

\subsection{Assessment of Inducible Nitric Oxide Synthase Mediated NO Accumulation}

RAW 264.7, a mouse leukemic macrophage cell line from the American Type Culture Collection (ATCC TIB-71) was cultured on endotoxin-free Dulbecco's Modified Eagle Medium (DMEM) supplemented with 10\% $(v / v)$ non-inactivated fetal bovine serum, $3.02 \mathrm{~g} / \mathrm{L}$ sodium bicarbonate, $100 \mu \mathrm{g} / \mathrm{mL}$ streptomycin and $100 \mathrm{U} / \mathrm{mL}$ penicillin at $37^{\circ} \mathrm{C}$ in a humidified atmosphere of $95 \%$ air and $5 \% \mathrm{CO}_{2}$ (carbon dioxide). During the experiments, cells were monitored through microscope observations to detect any morphological changes. Experiments were carried out at least three times.

Cells were incubated with several concentrations of the calendula oil (from 16 to $147 \mu \mathrm{L} / \mathrm{mL})$, in the absence or presence of LPS $(50 \mathrm{ng} / \mathrm{mL})$ for $24 \mathrm{~h}$ at $37^{\circ} \mathrm{C}$. Thereafter, culture supernatants were removed and accumulated NO, as a measure of NOS activity, was assessed in cell-free culture supernatants by the Griess reaction, as previously reported [17].

\subsection{Statistical Analysis}

The statistical analysis was performed with GraphPad Prism8 for Windows (GraphPad Software, San Diego, CA, USA; www.graphpad.com.) The results were expressed as mean \pm standard error of the mean (SEM) of, at least, three independent experiments. Multiple group comparisons were performed using one-way ANOVA analysis, with a Dunnett's multiple comparison post-test. The statistical significance levels were: ${ }^{*} p<0.05,{ }^{* *} p<0.01$.

\section{Results and Discussion}

We assessed the anti-inflammatory potential of the Calendula oil using LPS-stimulated macrophages, an in vitro model of inflammation. The effect on NO production, a canonical marker of inflammation, was analyzed by measuring the accumulation of nitrites in the culture medium. Moreover, the effect of the Calendula oil on macrophages viability was also tested. Our results show that nitrite production was significantly reduced in the presence of the Calendula oil, in a dose dependent way, attaining a decrease of $50 \%$ with $147 \mu \mathrm{L} / \mathrm{mL}$ of the oil (Figure 1b). Importantly, macrophages' viability was not affected by the tested concentrations of the Calendula oil $(16 \mu \mathrm{L} / \mathrm{mL}$ to $147 \mu \mathrm{L})$ (Figure $1 \mathrm{a})$, thus, proving the safety profile of the oil at concentrations exhibiting pharmacological activity.

The results on NO inhibition were statistically different for concentrations above $49 \mu \mathrm{L} / \mathrm{mL}$ control $(p<0.05)$, with a decrease of around $50 \%$ at $147 \mu \mathrm{L} / \mathrm{mL}$.

Terpenoids and flavonoids have been considered the bioactive constituents of this plant [10]. Using the same model, other authors verified that bisabolol, kaempferol, quercetin and isorhamnetin 3-O- $\beta$-D-glucopyranoside inhibited nitric oxide production by iNOS [18-21]. Other botanical preparations, which are used in topical formulations for inflamed and injured skin, have been evaluated regarding their iNOS inhibiting ability. Gupta et al. showed that an aqueous Matricaria chamomila L. flower extract, caused a modest, but statistically significant decrease in the endogenous NO levels in RAW 264.7 cells exposed to LPS, which was more pronounced over $20 \mu \mathrm{g} / \mathrm{mL}$ [22]. Another study found that a methanolic Centella asiatica L. extract suppressed NO production by RAW 264.7 cells exposed to LPS in a dose-dependent manner with a maximum inhibitory effect up to $20 \%$, in comparison with control [23]. Therefore, the test Calendula extract present a more potent 
iNOS inhibiting ability than Matricaria chamomila L. flower extract and Centella asiatica L. extract.

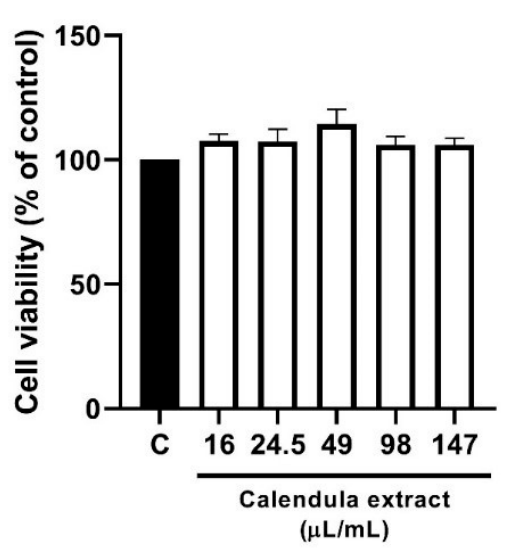

(a)

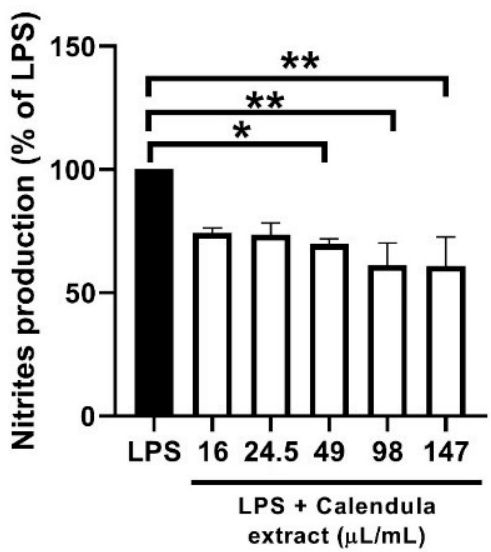

(b)

Figure 1. (a) Effect of Calendula oil on macrophages viability. The assessment of metabolically active cells was performed using a resazurin bioassay. The results are expressed as a percentage of resazurin reduction relatively to control cells. Each value represents the mean \pm SEM from three independent experiments. (b) Effect of Calendula oil on NO production. Anti-inflammatory activity was measured as inhibition of nitrite production, quantified by the Griess assay. The results are expressed as a percentage of nitrite production relatively to LPS. Each value represents the mean \pm SEM from three independent experiments. ${ }^{*} p<0.05,{ }^{* *} p<0.01$.

Several skin cells produce NO, and constitutive low levels of NO production seem to play a role in the maintenance of barrier function. Regulation of vasodilation, melanogenesis, and protective responses against invading pathogens are some examples of the biologic activity of NO in the skin. The dysregulation of the NO signaling cascade has been shown to be associated with several conditions and diseases (e.g., inflammatory, hyperproliferative, autoimmune skin diseases, and skin cancer). Therefore, compounds able to inhibit NO production may provide opportunities for the development of new mechanism-based therapies for skin inflammatory conditions [24]. In this view, topical medicines with Calendula flower extract can present novel benefits, in addition to the already established uses such as natural anti-inflammatory for the treatment of first-degree burns, scalds, bruises, wounds, and rashes, such as diaper dermatitis [25-27]. Moreover, its antimicrobial effect over both gram-positive and gram-negative may help prevent skin infection resulting from these conditions [28].

Cosmetic products containing this extract can also present a considerable advantage as adjunctive skin care in the treatment of diseases associated with iNOS activation, such as vitiligo, allergic and irritant contact dermatitis, rosacea, and melasma [29-35].

The experimental evidence, obtained in this work, provides scientific evidence for several reported uses of Calendula extract in cosmetic products, such as in after-sun products. UV-B exposure induces iNOS expression, while increasing the enzyme activity in skin endothelial cells, both directly and also through a TNF- $\alpha$-dependent mechanism [31]. Considering calendula's antioxidant, anti-inflammatory and wound healing activity, especially its ability for inhibiting NO production, the topical application of the flower extract is useful both for protecting the skin from sunburn and for ameliorating its symptoms, while preventing long-term consequences of UV-induced skin damage [28,30,31].

Noteworthy, this ingredient is likely to be proposed for the treatment and prevention of cancer therapy-induced skin-toxicity [36]. From the cutaneous toxicities experienced by patients, hand-foot syndrome (HFS) is among the most common [3]. Many chemotherapy agents can lead to HFS. The most commonly accepted theory of HFS pathogenesis involves direct toxicity of chemotherapeutic agents against acral epithelium, which leads to an 
inflammatory process due to overexpression of COX-2 in palms and plantar areas [37]. As described, inflammatory cells release prostaglandins with consequent increase in the expression of COX-2 which activates and induces oxidant generating enzymes, like NADPH oxidase, xanthine oxidase among others, which produce superoxide anion and other reactive nitrogen species like nitric oxide through activation of iNOS. [6] The use of Calendula could be part of a standardization process for HFS management since Calendula extract may inhibit pro-inflammatory cytokines and COX-2 and subsequent prostaglandin synthesis and, as shown in this work, it can also inhibit NO production $[6,13,38]$. Babaee et al. also showed that a Calendula extract gel could be effective in decreasing the intensity of radiotherapy-induced oropharyngeal mucositis [34].

\section{Conclusions}

Calendula extracts are used in a variety of cosmetics and preparations, especially for inflamed and injured skin, and have a long safety history. However, the anti-inflammatory mechanism of Calendula extracts is poorly understood. Therefore, this work investigated the ability of a commercial calendula flower extract to inhibit NO production on RAW 264.7 macrophages exposed to LPS. The results showed a dose-dependent NO inhibition up to $50 \%$, presenting a safety profile, thus, reinforcing the anti-inflammatory activity of calendula flower extract. Overall, this study supports the usefulness of Calendula oil in the treatment of injured skin and for conditions or diseases for which iNOS contributes to the pathophysiology, such as irritative and allergic contact dermatitis, vitiligo, rosacea, melasma, psoriasis and cutaneous toxicities derived from cancer treatment. The experimental evidence, herein, obtained is also useful in supporting the claims of cosmetic products containing this botanical ingredient.

Author Contributions: Conceptualization, I.F.A. and D.S.; methodology, M.T.C. and D.S.; software, M.T.C. and D.S.; investigation, D.S.; writing — original draft preparation, M.S.F. and D.S.; writingreview and editing, D.S., M.S.F., M.T.C., I.F.A., J.M.S.-L.; supervision, M.T.C. and I.F.A.; funding acquisition, J.M.S.-L. All authors have read and agreed to the published version of the manuscript.

Funding: This work was supported by the Applied Molecular Biosciences Unit-UCIBIO which is financed by national funds from FCT/MCTES (UID/Multi/04378/2020) and by the European Regional Development Fund (ERDF), through the Centro 2020 Regional Operational Program under project CENTRO-01-0145-FEDER-000012 (HealthyAging2020). MS Ferreira acknowledges a doctoral grant from FCT ref. SFRH/BD/144864/2019.

Institutional Review Board Statement: Not applicable.

Informed Consent Statement: Not applicable.

Data Availability Statement: The data presented in this study are available in Figure 1.

Conflicts of Interest: The authors declare no conflict of interest. The funders had no role in the design of the study; in the collection, analyses, or interpretation of data; in the writing of the manuscript, or in the decision to publish the results.

\section{References}

1. Neukirch, H.; D’Ambrosio, M.; Dalla, V.J.; Guerriero, A. Simultaneous quantitative determination of eight triterpenoid monoesters from flowers of 10 varieties of Calendula officinalis L. and characterisation of a new triterpenoid monoester. Phytochem. Anal. 2004, 15, 30-35. [CrossRef]

2. Jadoon, S.; Karim, S.; Bin, A.M.H.; Akram, M.R.; Khan, A.K.; Malik, A.; Chen, C.; Murtaza, G. Anti-Aging potential of phytoextract loaded-pharmaceutical creams for human skin cell longetivity. Oxid. Med. Cell. Longev. 2015, 2015, 709628. [CrossRef]

3. Komissarenko, N.F.; Chernobai, V.T.; Derkach, A.I. Flavonoids of inflorescences of Calendula officinalis. Chem. Nat. Compd. 1988, 24, 675-680. [CrossRef]

4. Agatonovic-Kustrin, S.; Babazadeh, O.D.; Morton, D.W.; Yusof, A.P. Rapid evaluation and comparison of natural products and antioxidant activity in calendula, feverfew, and German chamomile extracts. J. Chromatogr. A 2015, 1385, 103-110. [CrossRef] [PubMed]

5. $\quad$ Parente, L.M.; Andrade, M.A.; Brito, L.A.; Moura, V.M.; Miguel, M.P.; Lino-Junior, R.S.; Tresvenzol, L.F.; Paula, J.R.; Paulo, N.M. Angiogenic activity of Calendula officinalis flowers L. in rats. Acta Cir. Bras. 2011, 26, 19-24. [CrossRef] 
6. Preethi, K.C.; Kuttan, G.; Kuttan, R. Anti-inflammatory activity of flower extract of Calendula officinalis Linn. and its possible mechanism of action. Indian J. Exp. Biol. 2009, 47, 113-120.

7. Efstratiou, E.; Hussain, A.I.; Nigam, P.S.; Moore, J.E.; Ayub, M.A.; Rao, J.R. Antimicrobial activity of Calendula officinalis petal extracts against fungi, as well as gram-negative and gram-positive clinical pathogens. Complement. Ther. Clin. Pract. 2012, 18, 173-176. [CrossRef]

8. Khairnar, M.S.; Pawar, B.; Marawar, P.P.; Mani, A. Evaluation of Calendula officinalis as an anti-plaque and anti-gingivitis agent. J. Indian Soc. Periodontol. 2013, 17, 741-747. [CrossRef] [PubMed]

9. Andersen, F.A.; Bergfeld, W.F.; Belsito, D.V.; Hill, R.A.; Klaassen, C.D.; Liebler, D.C.; Marks, J.G., Jr.; Shank, R.C.; Slaga, T.J.; Snyder, P.W. Final report of the cosmetic ingredient review expert panel amended safety assessment of Calendula officinalis-derived cosmetic ingredients. Int. J. Toxicol. 2010, 29, 221-243. [CrossRef] [PubMed]

10. Stegemann, S. Patient centric drug product design in modern drug delivery as an opportunity to increase safety and effectiveness. Expert. Opin. Drug. Deliv. 2018, 15, 619-627. [CrossRef] [PubMed]

11. Della Loggia, R.; Tubaro, A.; Sosa, S.; Becker, H.; Saar, S.; Isaac, O. The role of triterpenoids in the topical anti-inflammatory activity of Calendula officinalis flowers. Planta. Med. 1994, 60, 516-520. [CrossRef] [PubMed]

12. Ukiya, M.; Akihisa, T.; Yasukawa, K.; Tokuda, H.; Suzuki, T.; Kimura, Y. Anti-inflammatory, anti-tumor-promoting, and cytotoxic activities of constituents of marigold (Calendula officinalis) flowers. J. Nat. Prod. 2006, 69, 1692-1696. [CrossRef] [PubMed]

13. Singh, M.K.; Sahu, P.; Nagori, K.; Dewangan, D.; Kumar, T.; Alexander, A.; Badwaik, H.; Tripathi, D.K. Organoleptic properties in-vitro and in-vivo pharmacological activities of Calendula officinalis linn: An over review. J. Chem. Pharm. 2011, 3, 655-663.

14. Gorchakova, T.V.; Suprun, I.V.; Sobenin, I.A.; Orekhov, A.N. Use of natural products in anticytokine therapy. Bull. Exp. Biol. Med. 2007, 143, 316-319. [CrossRef]

15. Braga, P.C.; Dal Sasso, M.; Culici, M.; Spallino, A.; Falchi, M.; Bertelli, A.; Morelli, R.; Lo Scalzo, R. Antioxidant activity of Calendula officinalis extract: Inhibitory effects on chemiluminescence of human neutrophil bursts and electron paramagnetic resonance spectroscopy. Pharmacology 2009, 83, 348-355. [CrossRef]

16. Cinelli, M.A.; Do, H.T.; Miley, G.P.; Silverman, R.B. Inducible nitric oxide synthase: Regulation, structure, and inhibition. Med. Res. Rev. 2020, 40, 158-189. [CrossRef]

17. Silva, A.; Oliveira, A.S.; Vaz, C.V.; Correia, S.; Ferreira, R.; Breitenfeld, L.; Martinez-de-Oliveira, J.; Palmeira-de-Oliveira, R.; Pereira, C.M.F.; Palmeira-de-Oliveira, A.; et al. Anti-inflammatory potential of Portuguese thermal waters. Sci. Rep. 2020, 10, 22313. [CrossRef]

18. Wadsworth, T.L.; Koop, D.R. Effects of the wine polyphenolics quercetin and resveratrol on pro-inflammatory cytokine expression in RAW 264.7 macrophages. Biochem. Pharmacol. 1999, 57, 941-949. [CrossRef]

19. Kim, Y.A.; Kong, C.S.; Um, Y.R.; Lim, S.Y.; Yea, S.S.; Seo, Y. Evaluation of Salicornia herbacea as a potential antioxidant and anti-inflammatory agent. J. Med. Food. 2009, 12, 661-668. [CrossRef]

20. Kim, S.; Jung, E.; Kim, J.H.; Park, Y.H.; Lee, J.; Park, D. Inhibitory effects of (-)-alpha-bisabolol on LPS-induced inflammatory response in RAW264.7 macrophages. Food. Chem. Toxicol. 2011, 49, 2580-2585. [CrossRef] [PubMed]

21. Liang, Y.C.; Huang, Y.T.; Tsai, S.H.; Lin-Shiau, S.Y.; Chen, C.F.; Lin, J.K. Suppression of inducible cyclooxygenase and inducible nitric oxide synthase by apigenin and related flavonoids in mouse macrophages. Carcinogenesis 1999, 20, 1945-1952. [CrossRef]

22. Bhaskaran, N.; Shukla, S.; Srivastava, J.K.; Gupta, S. Chamomile: An anti-inflammatory agent inhibits inducible nitric oxide synthase expression by blocking RelA/p65 activity. Int. J. Mol. Med. 2010, 26, 935-940. [CrossRef]

23. Cho, Y.C.; Vuong, H.L.; Ha, J.; Lee, S.; Park, J.; Wibow, A.E.; Cho, S. Inhibition of inflammatory responses by centella asiatica via suppression of IRAK1-TAK1 in mouse macrophages. Am. J. Chin. Med. 2020, 48, 1103-1120. [CrossRef]

24. Bruch-Gerharz, D.; Ruzicka, T.; Kolb-Bachofen, V. Nitric oxide in human skin: Current status and future prospects. J. Investig. Derm. 1998, 110, 1-7. [CrossRef]

25. Re, T.A.; Mooney, D.; Antignac, E.; Dufour, E.; Bark, I.; Srinivasan, V.; Nohynek, G. Application of the threshold of toxicological concern approach for the safety evaluation of calendula flower (Calendula officinalis) petals and extracts used in cosmetic and personal care products. Food. Chem. Toxicol. 2009, 47, 1246-1254. [CrossRef] [PubMed]

26. Sharifi-Heris, Z.; Farahani, L.A.; Haghani, H.; Abdoli-Oskouee, S.; Hasanpoor-Azghady, S.B. Comparison the effects of topical application of olive and calendula ointments on children's diaper dermatitis: A triple-blind randomized clinical trial. Dermatol. Ther. 2018, 31, e12731. [CrossRef]

27. Quave, C.L. Wound healing with botanicals: A review and future perspectives. Curr. Dermatol. Rep. 2018, 7, 287-295. [CrossRef]

28. Leach, M.J. Calendula officinalis and wound healing: A systematic review. Wounds 2008, 20, 236-243.

29. Mansourpour, H.; Ziari, K.; Motamedi, S.K.; Poor, A.H. Therapeutic effects of iNOS inhibition against vitiligo in an animal model. Eur. J. Transl. Myol. 2019, 29, 8383. [CrossRef]

30. Jha, A.K.; Karki, S. Pigmentary disorders; vitiligo and melasma in context of south asian countries: A psychosocio-cosmetic challenge. Int. J. Dermatol. Clin. Res. 2015, 1, 24-30. [CrossRef]

31. Suschek, C.V.; Mahotka, C.; Schnorr, O.; Kolb-Bachofen, V. UVB radiation-mediated expression of inducible nitric oxide synthase activity and the augmenting role of co-induced TNF-alpha in human skin endothelial cells. J. Investig. Dermatol. 2004, 123, 950-957. [CrossRef] [PubMed] 
32. Moura, A.K.A.; Guedes, F.; Rivitti-Machado, M.C.; Sotto, M.N. Inate immunity in rosacea. Langerhans cells, plasmacytoid dentritic cells, toll-like receptors and inducible oxide nitric synthase (iNOS) expression in skin specimens: Case-control study. Arch. Dermatol. Res. 2018, 310, 139-146. [CrossRef] [PubMed]

33. Dilek, N.; Dilek, A.R.; Taskin, Y.; Erkinuresin, T.; Yalcin, O.; Saral, Y. Contribution of myeloperoxidase and inducible nitric oxide synthase to pathogenesis of psoriasis. Postepy. Dermatol. Alergol. 2016, 33, 435-439. [CrossRef] [PubMed]

34. Babaee, N.; Moslemi, D.; Khalilpour, M.; Vejdani, F.; Moghadamnia, Y.; Bijani, A.; Baradaran, M.; Kazemi, M.T.; Khalilpour, A.; Pouramir, M.; et al. Antioxidant capacity of calendula officinalis flowers extract and prevention of radiation induced oropharyngeal mucositis in patients with head and neck cancers: A randomized controlled clinical study. Daru 2013, 21, 18. [CrossRef] [PubMed]

35. Ormerod, A.D.; Dwyer, C.M.; Reid, A.; Copeland, P.; Thompson, W.D. Inducible nitric oxide synthase demonstrated in allergic and irritant contact dermatitis. Acta. Derm. Venereol. 1997, 77, 436-440. [CrossRef] [PubMed]

36. Kodiyan, J.; Amber, K.T. A review of the use of topical Calendula in the prevention and treatment of radiotherapy-induced skin reactions. Antioxidants 2015, 4, 293-303. [CrossRef] [PubMed]

37. Lou, Y.; Wang, Q.; Zheng, J.; Hu, H.; Liu, L.; Hong, D.; Zeng, S. Possible pathways of capecitabine-induced hand-foot syndrome. Chem. Res. Toxicol. 2016, 29, 1591-1601. [CrossRef]

38. Hamalainen, M.; Nieminen, R.; Vuorela, P.; Heinonen, M.; Moilanen, E. Anti-inflammatory effects of flavonoids: Genistein, kaempferol, quercetin, and daidzein inhibit STAT-1 and NF-kappaB activations, whereas flavone, isorhamnetin, naringenin, and pelargonidin inhibit only NF-kappaB activation along with their inhibitory effect on iNOS expression and NO production in activated macrophages. Mediat. Inflamm. 2007, 2007, 45673. [CrossRef] 